RESEARCH ARTICLE

\title{
An ideal fatty acid composition for human health: Hemp (Cannabis sativa L.) seed
}

\section{Ezgi Aytaç}

Department of Plant Sciences, Faculty of Agriculture and Natural Sciences Konya Food and Agriculture University, Konya 42080, Turkey

\section{Check for updates}

Correspondence to: Ezgi Aytaç, Department of Plant Sciences, Faculty of Agriculture and Natural Sciences Konya Food and Agriculture University, Konya 42080, Turkey; E-mail: Ezgi.Aytac@gidatarim.edu.tr

Received: May 6, 2021;

Accepted: July 18, 2021;

Published: July 21, 2021

Citation: Aytaç E. An ideal fatty acid composition for human health: Hemp (Cannabis sativa L.) seed. Chem Rep, 2021, 3(1): 188-194.

https://doi.org/10.25082/CR.2021.01.003

Copyright: (02021 Ezgi Aytaç. This is an open access article distributed under the terms of the Creative Commons Attribution License, which permits unrestricted use, distribution, and reproduction in any medium, provided the original author and source are credited.

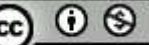

\begin{abstract}
The objective of this study was to show and crosscheck the seed yield and oil composition of three different seeds growing in different regions of Turkey. Extraction with n-hexane solvent indicated that there were differences in terms of oil yield between the regions. The average oil yield was $33.8 \%$ and $33.0 \%$ seed-I, $35.7 \%$ seed-II (Region-a) and $32.6 \%$ seedIII (Region-b) oil yields were obtained. The highest fatty acid content of hemp was found as: linoleic acid (average 55.24\%) followed by oleic acid (average 17.20\%) and $\alpha$-linolenic acid (average $16.02 \%$ ). Crude ash, total dry matter and crude protein analyzes were also performed. It was observed that the hemp seed oil yield was dependent on the extraction whereas extraction had no influence on the fatty acid content. Comparison of the seed oil yield with the other studies indicated that geographical region as well as the extraction method may affect the seed oil yield.
\end{abstract}

Keywords: extraction, GC-FID, hemp, linoleic acid, $\alpha$-linolenic acid

\section{Introduction}

The hemp, Cannabis sativa L., (Cannabinaceae) is a herbaceous plant which grows all year around and also reach up to five meters with an average of 6 months growing period. Normally, it grows in the Asian countries such as Iran, Pakistan, China, India, and Russia (Western and Central Asia) and is also dispensed in Africa and Europe. Turkey is one of the important natural environments of this precious plant, as its savage and planted populations are situated in varied countries of Turkey. It is an agricultural plant that has been cultivated for about 5000 years for different goals i.e., fiber and oil [1]. The European Commission Plant Variety Database accepts the hemp as an agricultural plant with the 74 varieties [2]. Europe is the leader of production with $88 \%$ of total hemp, and also France is the leader of Europe [3]. Hemp is a multi-purpose product that serves many areas such as cosmetics, health, functional food, paper making, fiber, textile and biofuels [4-6]. It is also one of the main sources of hundreds of bioactive compounds such as, terpenes, cannabinoids, flavonoids and polyunsaturated fatty acids [7].

The cannabinoids are the most studied group for hemp plant, which contains 480 chemical subclasses [8]. On the other hand, hemp seed contains $25 \%-35 \%$ oil, $20 \%-25 \%$ protein, $20 \%-$ $30 \%$ carbohydrate, and $10 \%-15 \%$ insoluble fiber [9]. While $50-70 \%$ of the total fatty acid amount of hemp seed oil is linoleic acid (omega-6), and $15-25 \%$ is $\alpha$-linolenic acid (omega 3) [10]. Hemp seed oil is known to be the unique with an ideal ratio (3: 1) of omega- 6 and omega-3, which performs an worthy part in improving human wellness by reducing diseases such as sclerosis, high blood pressure, high cholesterol levels and cancer [11]. The presence of long chain polyunsaturated fatty acids is a special case for hemp seed, as this property is not seen in any other industrial oilseed products. Hemp cultivation has become widespread with the increase in fiber and oil use in recent years. It should not be forgotten that fat-soluble vitamins are vital for health, especially considering the health benefits and nutritional benefits of hemp seeds and its oil [12].

Climatic and agricultural conditions may cause differences in fatty acid contents in seed content. There are differences in different areas, different regions, and even between different samples in the same region, which show the differences in the fatty acid content of hemp oil [1,13-15]. Changes in light, temperature and humidity affect fatty acid synthesis in plants, and this causes seeds grown in regions with different characteristics to contain different oils [16].

Cold pressing and solvent extraction are the most commonly used methods for obtaining hemp seed oil, but the most used after these are n-hexane and supercritical $\mathrm{CO}_{2}$ extraction. Compared to solvent extraction, although a better quality oil is obtained with cold pressing, its yield is lower. The fact that the part that cannot be extracted is still in the seed decreases the yield. It is known that $20-40 \%$ of the oil may remain in the seed after cold pressing [17]. 
Although solvent extraction is a more efficient and comparatively inexpensive technique, it requires a purification as there may be residual solvent in the final product. According to these techniques, supercritical $\mathrm{CO}_{2}$ extraction and liquid $\mathrm{CO}_{2}$ extraction are more innovative and harmless to the environment. Comparing the supercritical carbon dioxide extraction with the soxhlet extraction using n-hexane as an extracting solvent, Da Port et al. [18] showed that the extraction method did not affect the fatty acid composition of the oils, but a higher oil yield was obtained by soxhlet extraction.

According to European Union Law, fewer solvents can be used for alimentary oil extractions and $n$-hexane is the best of these solvents [19]. There is a great connection between oil yield and solvent polarity. The most apolar solvent, with regard to Reichardt [20], is n-hexane $\left(\mathrm{E}_{T}^{N}=0.009\right)$, gives the most oil yield, generally as usual with European Union Law. Acetone $\left(\mathrm{E}_{T}{ }^{N}=0.355\right)$, which is more polar than $\mathrm{n}$-hexane, yielded lower oil amounts than n-hexane. For the mixture of acetone and $\mathrm{n}$-hexane, a yield is expected in the middle of the yield obtained when used separately for extraction. Ethanol $\left(\mathrm{E}_{T}{ }^{N}=0.654\right)$ and water $\left(\mathrm{E}_{T}{ }^{N}=1.000\right)$, the most polar solvents, obtained the lowest oil yields. In all extraction, the more polar the solvent, the lower the oil yield [21].

An efficient extraction procedure is determined from the above rules. Especially, in the extraction procedures, extraction efficiency, less solvent use, short extraction time, low temperatures and low cost are important criterias.

Increasing interest in hemp seed in recent years, studies have become very important. The purpose of this study was to show the most effective way to make an industry-appropriate extraction process. Based on the data in the literature, n-hexane which is the most used solvent in the industry for oil extraction was used in this study to extract oil from hemp seed. In this study, the different hemp seeds were used to compare the oil yield and fatty acid contents extracted by with n-hexane which is selected according to the industrial suitability.

\section{Material and methods}

\subsection{Chemicals}

All chemicals used were of analytical grade purchased from Sigma Aldrich (Germany).

\subsection{Sample preparation}

Three different seeds were taken from two different cities of Turkey. Seeds taken from three different herbalists were blended at 3 degrees speed for 5 minutes using Waring Commercial Laboratory Blender (Sigma, Germany). Then pieces of 10 grams from each ground seed were weighed.

Seed I-Ankara, Turkey;

Seed II- Konya (Region-a), Turkey;

Seed III- Konya (Region-b), Turkey.

\subsection{Extraction procedure}

In terms of industrial applicability and high efficiency in many areas, soxhlet system with $\mathrm{n}$-hexane was used for extraction. All extractions were conducted in triplicates and averages of the results were used.

Soxhlet apparatus were used for extraction of $10.0 \mathrm{~g}$ of material. Weighed samples were put into a cellulose thimble. The filled thimble was settle down in a $150 \mathrm{~mL}$ soxhlet extractor. The grounded seed material was defatted for 5 hours at $70^{\circ} \mathrm{C}$ using $100 \mathrm{~mL}$ of $\mathrm{n}$-hexane [22]. After cooling to ambient temperature, the extract was relayed to a $500 \mathrm{~mL}$ volumetric flask, the solvent was removed in a rotary evaporator at $50^{\circ} \mathrm{C}$ (Hei-VAP Precision, Heidolph, Germany). The oil obtained from the extraction was analyzed in gas chromatography equipped with flame ionization detector (GC-FID) system.

\subsection{Determination of fatty acids with gas chromatography (GC- FID)}

In order to obtain the fatty acid content of the oil samples, fatty acids were primarily converted into methyl esters. The samples were syringed into GC-FID. The fatty acid composition was analyzed with gas chromatography which equipped with a flame ionization detector (FID) (Shimadzu, Kyoto, Japan) and Rxi-5 Sil MS 30 Meter 0.25 mm ID $0.25 \mu \mathrm{m}$ df column (RESTEK). 
The carrier and supporting gas were helium $(30 \mathrm{~mL} / \mathrm{min})$ and air $(350 \mathrm{~mL} / \mathrm{min})$, respectively. The column temperature was set $40^{\circ} \mathrm{C}$ for $2 \mathrm{~min}$ and increasing to $240^{\circ} \mathrm{C}$ with $5^{\circ} \mathrm{C} / \mathrm{min}$ rate The injection was conducted at $250^{\circ} \mathrm{C}$ with split ratio of $1 / 10$ and injection volume was $2 \mu \mathrm{L}$. Each fatty acid peak was determined by comparison their retention times with standard fatty acids peaks. The results were expressed as relative percentages of total fatty acids.

\subsection{Determination of seed quality parameters}

The ash analysis should be performed for microbial stability, nutrition, taste, appearance, texture and the stability of foods.

The total dry matter amount analysis should be made for the characteristics such as the stability of the food, the determination of the storage time and sensory quality.

The crude protein analysis should be performed in order to determine the conformity of the foodstuff to the current quality standards, the nutritional value of the foodstuff, and some functional technological properties of proteins (emulsion capacity, water and fat binding capacity, foaming, gel strength, solubility, etc.).

\subsubsection{Determination of ash content}

First, the crucibles are dried in an ash furnace at $500-600^{\circ} \mathrm{C}$. The crucibles are cooled in a desiccator and weighed $\left(\mathrm{Y}_{1}\right) .3-4 \mathrm{~g}$ sample is placed in the crucible and weighed $\left(\mathrm{Y}_{2}\right)$. Until white ash is formed in the ash furnace, it is burned at $500-600^{\circ} \mathrm{C}$ depending on the food. It is weighed after cooling in the desiccator $\left(\mathrm{Y}_{3}\right)$. The calculation is done according to Equation (1).

$$
\operatorname{Ash} \%=\left[\left(Y_{3}-Y_{1}\right) /\left(Y_{2}-Y_{1}\right)\right] \times 100
$$

\subsubsection{Determination of total dry matter}

The part remaining after removing the water is often referred to as total dry matter. The moisture content of some products is determined by standard procedures for standard conformity control.

The drying container is dried and brought to room temperature in the desiccator. The cooled drying container is tared. (G) Prepared samples are placed in the drying container 3-5 g and weighed. $\left(\mathrm{G}_{1}\right)$ The samples are kept at the appropriate temperature $\left(105^{\circ} \mathrm{C}\right)$, until they reach constant weight $\left(\mathrm{G}_{2}\right)$. The calculation is done according to Equation (2) and Equation (3).

$$
\begin{gathered}
\text { Moisture } \%=\left[\left(\mathrm{G}_{2}-\mathrm{G}\right) /\left(\mathrm{G}_{1}-\mathrm{G}\right)\right] \times 100 \\
\text { Total dry matter }=100-\text { moisture } \%
\end{gathered}
$$

\subsubsection{Determination of crude protein content}

Protein ratio, which is generally determined by the amount of nitrogen, is called crude protein.

Analysis was made with Dumatherm, Gerhardt. Once the sample is weighed (about 150$200 \mathrm{mg}$ ) and refining of any air bubbles, it is heated in a high temperature oven and swiftly burned in the existence of oxygen at about $1000^{\circ} \mathrm{C}$. This causes to the leave off matters such as carbon dioxide, water, nitrogen dioxide and, above all, nitrogen as several oxides (NyOx). The combustion products are saved and permitted to equilibrate. The gas mixture is passed over hot copper to remove any oxygen and convert nitrogen oxides into molecular nitrogen. The sample is passed through traps that remove water and carbon dioxide. The measured signal from the thermal conductivity detector for the sample can then be converted into nitrogen content.

\section{Results and discussion}

\subsection{Oil yield}

Oil yield (\%) was calculated by formula below (Equation (4)). All analyses were done in triplicates.

$$
\text { Oil yield }(\%)=\text { Extracted oil weight }(\mathrm{g}) / \text { Total oil }(\mathrm{g}) \times 100
$$

It was observed that seed-II in Konya (Region-a) had the highest $(35.70 \%)$ oil content while seed-III in Konya (Region-b) had the lowest (32.60\%). Oil content of hemp seed was found as 
$31.79 \%$ in an earlier study from Turkey [13] which was slightly lower than the average value $(33.80 \%)$ obtained in this study. Moreover, this average value was much higher than the value reported (28.87\%) for the seeds grown in different regions of Pakistan [1]. The oil content of the seeds grown in different regions of Iran was declared as 33.33\% [16]. This may be attributed to climate similarity since the regions of Iran, and Konya and Ankara regions in Turkey are similar. Semi-arid continental climate prevails in these regions. While the average temperature is $6^{\circ} \mathrm{C}$ in January, and hot weather with $33^{\circ} \mathrm{C}$ in July. The seed yield can be influenced by countless factors such as weather, soil type, nutrition, planting time, and harvest time [5,23]. The oil contents were influenced by the variety of hemp and region (Table 1).

Table 1 Comparison of oil yields of different seeds growing in different cities in Turkey

\begin{tabular}{lr}
\hline Seed Variety & Yield (\%) \\
\hline Seed-I & $33.00 \pm 0.12$ \\
Seed-II (Region-a) & $35.70 \pm 0.15$ \\
Seed-III (Region-b) & $32.60 \pm 0.14$ \\
\hline
\end{tabular}

Notes: Results are presented as mean \pm standard deviation obtained from three replicates

The previous studies about extraction methods for hemp seed oil are shown in Table 2 . Usually oil yields were between $20 \%-35 \%$. Average of this study (33.8\%) was in line with the overall results. Solvent extraction results with $\mathrm{n}$-hexane in this study were up to $10 \%$ higher compared references.

Table 2 Summary of the literature of hemp seed oil extractions by different techniques

\begin{tabular}{llll}
\hline Extraction Method & Solvent & Oil Yield \% & Reference \\
\hline Soxhlet & n-Hexane & $32.60-35.70$ & This study \\
Supercritical Fluids & $\mathrm{CO}_{2}$ & $26.25-37.50$ & (Kriese et al., 2004) \\
Supercritical Fluids & $\mathrm{CO}_{2}$ & $17.20-21.10$ & (Da Porto et al., 2012) \\
Supercritical Fluids & $\mathrm{CO}_{2}$ & 21.20 & (Da Porto et al., 2015) \\
Cold Pressing & - & $26.90-31.50$ & (Anwar et al., 2006) \\
Soxhlet & n-Hexane & $30.96-34.60$ & (Merzouki and Mesa, 1997) \\
Soxhlet & n-Hexane & 30.60 & (Da Porto et al., 2012) \\
Soxhlet & n-Hexane & $25.59-30.84$ & (Kostić et al., 2013) \\
Soxhlet & n-Hexane & 30.00 & (Da Porto et al., 2015) \\
Soxhlet & Ether & $25.30-29.70$ & (Vonapartis et al., 2015) \\
\hline
\end{tabular}

Especially when looking at the results of supercritical and cold pressing, there was a difference of half in terms of efficiency. When looking at all extractions with n-hexane, it was seen that the results were quite different from each other. The reason for this can be attributed to seasonal conditions, agricultural conditions, and different regions. When soxhlet extraction was compared in terms of solvents, it was seen that there was a difference between n-hexane and ether and we can see from the table that $n$-hexane results were better.

\subsection{Fatty acids composition of extracts}

The fatty acid profiles for all analyzed seeds are given in Table 3. A close similarity was observed between all hemp seeds which was not surprising. The hemp seed oil obtained with different regions contained very large amount of polyunsaturated fatty acids (Table 3). Gas chromatography showed that unsaturated fatty acids, linoleic (omega-6), $\alpha$-linolenic (omega-3) and oleic acids, were the main fractions of the fatty acids present in the analyzed hempseed oil, while the rest were the saturated fatty acids (Table 3 ). Similar fatty acid compositions have been reported for hempseed oils in the previous studies.

Linolenic acid, with the range of 54.97-55.47\%, was primary fatty acid in the extracts. In contents, particularly the essential omega- 6 and omega- 3 fatty acids were composing more than $70 \%$ of total fatty acids. The ratio between omega- 6 and omega- 3 fatty acids was optimum and well balanced, with a rate varying from 3.4 with seed-I and 3.5 with seed-II (Region-a).

Palmitic acid (between 6.31-6.45\%), which is a saturated fatty acid, oleic acid (between $16.13-18.31 \%$ ), which is an unsaturated fatty acid with a double bond, and several fatty acids with multiple double bonds (between $0.39-55.46 \%$ ), that is linoleic acid, $\alpha$-linolenic acid and $\delta$-linolenic acid, were all examined in the samples. This results were in agreement with the other studies [1,22,24-26]. The amount of oleic acid (average 17.3\%) were higher than previous studies. In 2020, according to Aiello et al. [26] results of the research conducted by hexane extraction, the fatty acid content in hemp seed was quite compatible with our results. And at the 
Table 3 Fatty acid profiles of different seeds obtained by different regions

\begin{tabular}{lccc}
\hline \multirow{2}{*}{ Compounds } & \multicolumn{3}{c}{ Seed Variety } \\
\cline { 2 - 4 } & Seed-I & Seed-II (Region-a) & Seed-III (Region-b) \\
\hline Myristic Acid (C14:0) & $0.04 \pm 0.12$ & $0.04 \pm 0.07$ & $0.04 \pm 0.10$ \\
Palmitic Acid (C16:0) & $6.31 \pm 0.08$ & $6.37 \pm 0.01$ & $6.45 \pm 0.05$ \\
Stearic Acid (C18:0) & $2.65 \pm 0.06$ & $2.71 \pm 0.05$ & $2.46 \pm 0.03$ \\
Oleic Acid (C18:1n9c) & $17.40 \pm 0.16$ & $18.31 \pm 0.12$ & $16.14 \pm 0.09$ \\
Linoleic Acid (C18:2n6c) & $55.29 \pm 0.18$ & $54.97 \pm 0.15$ & $55.47 \pm 0.17$ \\
$\delta$ - Linolenic Acid (C18:3n6) & $0.42 \pm 0.03$ & $0.39 \pm 0.04$ & $0.43 \pm 0.02$ \\
$\alpha$-Linolenic Acid (C18:3n6) & $16.29 \pm 0.13$ & $15.51 \pm 0.09$ & $16.28 \pm 0.04$ \\
\hline
\end{tabular}

Notes: Results are presented as mean \pm standard deviation obtained from three replicates

same time, it was seen in that publication that the extraction method has no effect on the fatty acid content.

The beneficial effect of fatty acids on human health is known, especially linolenic acid has anti-hypertension, anti-thrombotic, anti-cancer, and anti-inflammatory effects [18]. At the same time, studies have shown that oleic acid is beneficial for cancer, autoimmune diseases and wound healing, as well as the broad psychological effects [27].

\subsection{Evaluation of seed quality parameters}

Some quality parameters of hemp seed oil are given in Table 4 . Typical quality contents (\%) of hemp seed in this study were consistent with Callaway's review in 2004 [25].

Table 4 Comparison of quality parameters of different seeds

\begin{tabular}{lccc}
\hline \multirow{2}{*}{ Parameters } & \multicolumn{3}{c}{ Seed Variety } \\
\cline { 2 - 4 } & Seed-I & Seed-II (Region-a) & Seed-III (Region-b) \\
\hline Ash Content & $4.69 \pm 0.02$ & $4.74 \pm 0.01$ & $4.86 \pm 0.02$ \\
Total Dry Matter & $93.99 \pm 0.03$ & $93.76 \pm 0.04$ & $94.45 \pm 0.04$ \\
Crude Protein Content & $23.67 \pm 0.02$ & $22.77 \pm 0.01$ & $22.99 \pm 0.01$ \\
\hline
\end{tabular}

Notes: Results are presented as mean \pm standard deviation obtained from three replicates

The average ash content in the review was $5.6 \%$, average protein $24.8 \%$, and moisture $6.5 \%$. The results found in our study were very close to the average values.

\section{Conclusion}

This study showed that oil yields obtained by n-hexane solvent extraction from seeds taken from different regions were different, but the fatty acid content did not change even if the regions were different. And also, the type of extraction system had a bare effect on oil yields, although the fatty acid profiles were more or less similar in the different extracts. In addition, the ideal ratio (3:1) of omega- 6 and omega- 3 in all three regions was observed. Hemp seed is an excellent source of nutrition. Regardless of the region in which they grow, all hemp seeds contain quite a lot of polyunsaturated fatty acids, which are linoleic acid and $\alpha$-linolenic acid. The healing properties of hemp seed can be attributed to high levels of polyunsaturated fatty acids in the oil Referring to other studies in the literature that contains less amount of oleic acid, but the seed we received from three different regions in Turkey have been found to contain higher amounts of oleic acid.

\section{Conflict of interest and funding}

The author has declared no conflicts of interest for this article. This work supported by Project Grant Number: YÖN-2019/017 of Konya Food and Agriculture University.

\section{Acknowledgements}

The author thanks to Prof Dr. Mevlüt Mülayim for providing hemp seeds, Osman Altunbaş for assisting to seed quality parameters analysis in SAR-GEM, and also Prof. Dr. Sencer Buzrul for controlling and correcting the language of manuscript. 


\section{Author contributions}

The design of experiments, all the analysis, evaluations of results, and also drafting and writing manuscript were done by Dr. Ezgi Aytaç.

\section{References}

[1] Anwar F, Latif S and Ashraf M. Analytical characterization of hemp (Cannabis sativa) seed oil from different agro-ecological zones of Pakistan. Journal of the American Oil Chemists' Society, 2006 , 83(4): 323-329. https://doi.org/10.1007/s11746-006-1207-x

[2] European Commission, Plant variety catalogues, databases information systems, 2020.

[3] FAO, http://www.fao.org/faostat/en/data/QC, 2020.

[4] Amaducci S, Scordia D, Liu F, et al. Key cultivation techniques for hemp in Europe and China. Industrial Crops and Products, 2015, 68: 2-16. https://doi.org/10.1016/j.indcrop.2014.06.041

[5] Baldini M, Ferfuia C, Piani B, et al. The performance and potentiality of monoecious hemp (Cannabis sativa L.) cultivars as a multipurpose crop. Agronomy, 2018, 8(9): 162. https://doi.org/10.3390/agronomy8090162

[6] Salentijn EM, Zhang Q, Amaducci S, et al. New developments in fiber hemp (Cannabis sativa L.) breeding. Industrial crops and products, 2015, 68: 32-41 https://doi.org/10.1016/j.indcrop.2014.08.011

[7] Rao V, Menezes A and Viana G. Effect of myrcene on nociception in mice. Journal of pharmacy and pharmacology, 1990, 42(12): 877-878. https://doi.org/10.1111/j.2042-7158.1990.tb07046.x

[8] Drinić Z, Vidović S, Vladić J, et al. Effect of extraction solvent on total polyphenols content and antioxidant activity of Cannabis sativa L. Lekovite sirovine, 2018, 38: 17-21. https://doi.org/10.5937/leksir1838017D

[9] Wang XS, Tang CH, Yang XQ, et al. Characterization, amino acid composition and in vitro digestibility of hemp (Cannabis sativa L.) proteins. Food Chemistry, 2008, 107(1): 11-18. https://doi.org/10.1016/j.foodchem.2007.06.064

[10] Haji-Moradkhani A, Rezaei R and Moghimi M. Optimization of pulsed electric field-assisted oil extraction from cannabis seeds. Journal of Food Process Engineering, 2019, 42(4): e13028. https://doi.org/10.1111/jfpe.13028

[11] Da Porto C, Natolino A and Decorti D. Effect of ultrasound pre-treatment of hemp (Cannabis sativa L.) seed on supercritical CO2 extraction of oil. Journal of food science and technology, 2015, 52(3): $1748-1753$. https://doi.org/10.1007/s13197-013-1143-3

[12] Gurr MI, Harwood JL and Frayn KN. Lipid biochemistry, Springer, 2002.

[13] Bağcı E, Bruehl L, Aitzetmuller K, et al. A chemotaxonomic approach to the fatty acid and tocochromanol content of Cannabis sativa L.(Cannabaceae). Turkish Journal of Botany, 2003, 27(2): 141-147.

[14] Kriese U, Schumann E, Weber W, et al. Oil content, tocopherol composition and fatty acid patterns of the seeds of 51 Cannabis sativa L. genotypes. Euphytica, 2004, 137(3): 339-351. https://doi.org/10.1023/B:EUPH.0000040473.23941.76

[15] Leizer C, Ribnicky D, Poulev A, et al. The composition of hemp seed oil and its potential as an important source of nutrition. Journal of Nutraceuticals, functional \& medical foods, 2000, 2(4) $35-53$.

https://doi.org/10.1300/J133v02n04_04

[16] Vosulipur M, Modares H and Mohsennia M. Determination of the amount and types of fatty acids in Hemp oil of different parts of Iran. Iranian Journal of Chemistry, 2004, 23(2): 81-88. https://doi.org/10.1016/j.indcrop.2020.112397

[17] Matthäus B and Brühl L. Virgin hemp seed oil: An interesting niche product. European Journal of Lipid Science and Technology, 2008, 110(7): 655-661. https://doi.org/10.1002/ejlt.200700311

[18] Da Porto C, Decorti D and Tubaro F. Fatty acid composition and oxidation stability of hemp (Cannabis sativa L.) seed oil extracted by supercritical carbon dioxide. Industrial Crops and Products, 2012 36(1): 401-404. https://doi.org/10.1016/j.indcrop.2011.09.015

[19] Official Journal of the European Community (OJEU), L 141(3) (2009).

[20] Reichardt C and Welton T. Solvents and solvent effects in organic chemistry. John Wiley \& Sons, 2011.

[21] Alonso-Esteban JI, González-Fernández MJ, Fabrikov D, et al. Hemp (Cannabis sativa L.) Varieties: Fatty Acid Profiles and Upgrading of $\gamma$-Linolenic Acid-Containing Hemp Seed Oils. European Journal of Lipid Science and Technology, 2020, 122(7): 1900445. https://doi.org/10.1002/ejlt.201900445

[22] Kostić MD, Joković NM, Stamenković OS, et al. Optimization of hempseed oil extraction by nhexane. Industrial crops and products, 2013, 48: 133-143. https://doi.org/10.1016/j.indcrop.2013.04.028 
[23] Panayiota P, Ioanna K and Ilias T. Effect of Nitrogen Fertilization on Growth and Yield of Industrial Hemp (Cannabis sativa L.). Notulae Botanicae Horti Agrobotanici Cluj-Napoca, 2018, 46(1): $197-$ 201.

https://doi.org/10.15835/nbha46110862

[24] Su M, Yang R and Li M. Biodiesel production from hempseed oil using alkaline earth metal oxides supporting copper oxide as bi-functional catalysts for transesterification and selective hydrogenation. Fuel, 2013, 103: 398-407. https://doi.org/10.1016/j.fuel.2012.07.009

[25] Callaway J. Hempseed as a nutritional resource: An overview. Euphytica, 2004, 140(1-2): 65-72. https://doi.org/10.1007/s10681-004-4811-6

[26] Aiello A, Pizzolongo F, Scognamiglio G, et al. Effects of supercritical and liquid carbon dioxide extraction on hemp (Cannabis sativa L.) seed oil. International Journal of Food Science \& Technology, 2020, 55(6): 2472-2480. https://doi.org/10.1111/ijfs.14498

[27] Sales-Campos H, Reis de Souza P, Crema Peghini B, et al. An overview of the modulatory effects of oleic acid in health and disease. Mini reviews in medicinal chemistry, 2013, 13(2): 201-210. https://doi.org/10.2174/1389557511313020003 